\title{
Review:
}

\section{Improving the Performance of Polymer Inclusion Membranes in Separation Process Using Alternative Base Polymers: A Review}

\author{
Fidelis Nitti ${ }^{1 *}$, Odi Theofilus Edison Selan ${ }^{1}$, Bosirul Hoque $^{2}$, David Tambaru ${ }^{1,2}$, and Muhammad Cholid \\ Djunaidi $^{3}$
}

${ }^{1}$ Department of Chemistry, University of Nusa Cendana, Jl. Adi Sucipto, Penfui, Kupang 85001, Nusa Tenggara Timur, Indonesia

${ }^{2}$ School of Chemistry, The University of Melbourne, Masson Road, Parkville 3052, Melbourne, Australia

${ }^{3}$ Department of Chemistry, Faculty of Science and Mathematics, Diponegoro University,

Jl. Prof. Soedarto S.H., Tembalang, Semarang 50275, Indonesia

* Corresponding author:

email:fnitti@staf.undana.ac.id

Received: August 9, 2021

Accepted: August 28, 2021

DOI: $10.22146 / \mathrm{ijc} .68311$

\begin{abstract}
Polymer inclusion membrane (PIM) has recently evolved as an alternative separation technique to conventional solvent extraction as it eliminates the use of toxic solvents, reduces separation cost, and simplifies the separation process. PIM is the new generation of a liquid membrane made by casting solution containing liquid phases (extractant and plasticizer/modifier) and base polymers. Despite its better performance and stability in comparison to the previous types of liquid membranes, PIM's robustness for applications on an industrial scale is still considered insufficient mainly due to its limited stability in the long-term separation process. In recent years, different approaches have been devoted to improving the stability of PIM while maintaining its performance. This review aims to summarize and evaluate the current literature on the improvement of the performance of PIMs with particular focus on the use of alternative base polymers, including non-conventional linear homopolymers, copolymers, or cross-linking polymers. Furthermore, more emphasis is given to the composition, fabrication process, and application of the PIMs. Finally, the performance of the PIMs with the alternative base polymers in terms of extraction rate and long-term stability is presented and compared to the PIMs fabricated using their corresponding common base polymers.
\end{abstract}

Keywords: polymer inclusion membrane; separation; alternative base polymer; copolymers; cross-linking polymers

\section{- INTRODUCTION}

Emerged as the most recent type of liquid membranes, polymer inclusion membranes (PIMs) have recently gained immense interests in the extraction and separation-based processes of a variety of metallic and non-metallic species owing to their advantages over other types of liquid membranes in terms of faster transport rate, high membrane stability and selectivity, and ease of fabrication [1-3]. The extraction and separation using PIMs generally mimic those of solvent extraction but without toxic and flammable solvents, thus considered a greener and more environmentally friendly separation technique. Furthermore, unlike separation using solvent extraction, the extraction and back-extraction using PIMs can be done simultaneously by sandwiching the PIM between the feed and receiving solutions [4-5]. This simultaneous extraction and the back-extraction process has been termed facilitated transport and has been utilized in the extraction and separation of various metallic and non-metallic species [4,6-7].

In addition to the extraction and separation applications, PIMs have also been utilized in several different applications, including monitoring environmental pollutants and chemical analysis, which 
involve sample pre-treatment (separation and preconcentration of analytes) and optical sensors for detection of a variety of chemical analytes $[5,8]$. In monitoring environmental pollutants, PIMs have been used as semipermeable membrane barriers in passive sampling devices to determine the time-weighted average (TWA) concentration of various analytes [9-11]. In sample pre-treatment, PIMs are used to separate the target analytes from the matrix interferences, manually using batch technique [12-13] or automatically in a flowthrough system [14-15], which results in a high enrichment factor and low limit of detection [8]. With additional colorimetric, fluorometric, or chemiluminescent reagents, PIMs have also been applied as optical sensors in sensing various chemical analytes that require simple and rapid on-site detection with high selectivity and sensitivity [16-17]. The wide range of applications of PIMs has been shown by the growing number of PIM papers published between 1992 and 2021, with a total of 382 papers (Fig. 1). A number of review papers have been devoted to providing the recent progress of PIM [1,4], with some were focused on the application in the chemical analysis $[5,8]$, removal of heavy metals [18-19], elimination of pharmaceutical and endocrinedisrupting chemicals [20], and recovery of precious metals from electronic waste [6].

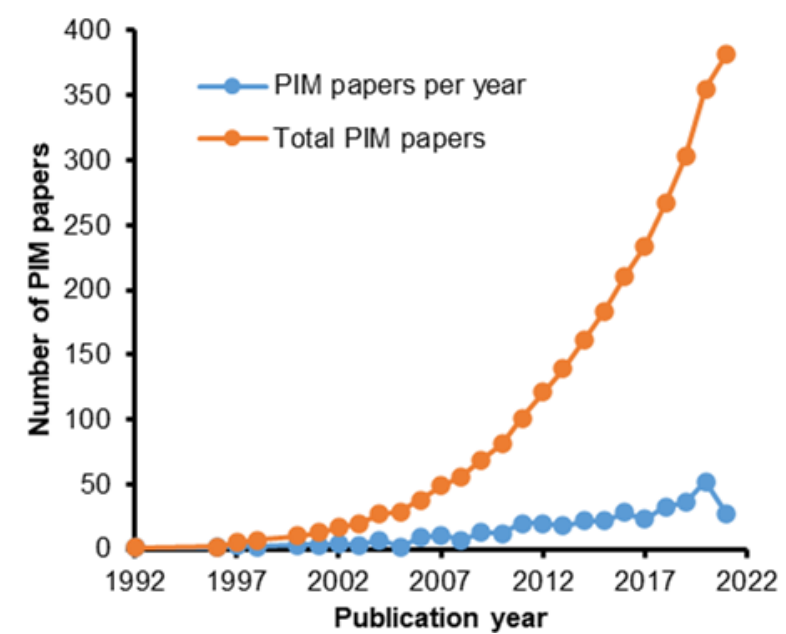

Fig 1. PIM papers published between 1992 and 2021. Details were obtained from the Scopus database with keywords "polymer inclusion membrane" as the search title
Like other types of liquid membranes, such as supported liquid membranes (SLMs), PIMs consist of a liquid phase encapsulated within the entangled polymeric chain of the base polymer. The liquid phase composes mainly of a liquid extractant that binds analytes. Among liquid phases, Aliquat 336 (a mixture of quaternary alkylammonium chlorides) and di-(2ethylhexyl) phosphoric acid (D2EHPA) are the most widely used. These extractants are known to have plasticizing properties, and hence in most cases, they can be used in PIMs without the requirement for an additional plasticizer [21-22]. However, adding a plasticizer or modifier is necessary to provide a sufficient degree of membrane plasticity and flexibility in other cases.

On the other hand, the base polymer acts as a polymeric backbone to hold the liquid phase and provide mechanical strength to the membrane. Most of the PIMs used in the past several years were made of two main homopolymers, PVC and CTA [1,4]. PIMs have been commonly prepared using a solvent evaporation technique which generally involves the dissolution of all the membrane components in a suitable solvent (i.e., tetrahydrofuran (THF) for PVC and dichloromethane (DCM) for CTA), followed by the solution casting and slow evaporation of the solvent $[10,23]$. PIMs can also be prepared through a phase inversion method that involves immersing nascent PIM casting solution into an immiscible solvent to remove the organic solvent [24]. A successful PIM production is indicated by its flexibility, transparent and homogenous appearance, which shows good compatibility between all the membrane components [1].

The increasing demand for using PIMs in the extraction and separation of a wide range of analytes in recent years is because of its potential elimination of the requirement for large volumes of solvents, as in solvent extraction. However, as described above, a small volume of non-sustainable and toxic solvents is still required during the fabrication process of PIMs $[1,4]$. Thus, to further comply with green chemistry principles, an effort has been made to either minimize the use of hazardous solvents or to replace them with more 
environmentally friendly solvents [25]. Alternatively, a greener PIM fabrication process has also been based on a thermal-compression technique, eliminating the need for solvents in the fabrication of PIMs. This technique applied high pressure to the thermally-melted PIM components to form thin layer PIMs [26]. While there is currently a limited number of greener solvents, reducing the PIM materials and the solvents by omitting the current scheme of single-use or one-time use PIMs is feasible. A multiple-use scheme can be achieved if the fabricated PIM poses high stability even under continuous and multicycle use. In this regard, a substantial reduction in the amount of materials and solvents required to fabricate the PIMs is possible if the PIMs are used on a larger scale. However, as reported in the literature, the transport efficiency of PIMs fabricated using the most commonly used base polymers, PVC and CTA, decreases after repeating use. This problem is mainly due to the instability of the PIMs, which is associated with the continuous leaching of the membrane liquid phase (extractant and plasticizer or modifier) into the aqueous phase(s) in contact with the membrane during the PIM's application (i.e., feed and receiving solutions). This problem is exacerbated because PIMs based on CTA and PVC base polymers exhibit poor stability due to their inherent properties. For instance, in strongly acidic and alkaline solutions, CTA undergoes a hydrolysis process and thus limits its potential use and regeneration, particularly if used in such an environment. On the other hand, PVC is prone to dehydrochlorination under alkaline conditions, resulting in turning the transparent PIMs to black color. This condition reveals that despite the broad range applicability of PIMs demonstrated under laboratory conditions, their robustness for long-term application on an industrial scale is considered insufficient.

Current research indicated that there had been several different approaches to deal with the leaching of the PIMs' liquid phase while maintaining the performance of the PIMs during their application. These include doping the membrane with reduced graphene oxide (rGO) [27], saturating the feed solution during the transport experiment with the same liquid extractant used in the PIMs [28], and incorporating a modifier with very low water solubility in the membrane composition [29]. However, despite their proven ability to prevent the leaching of PIMs' liquid phase for specific PIM compositions, most of these techniques could not be generally applicable, and thus there have been limited reports available in the literature. More recently, an effort to prevent the leaching of PIMs' liquid phase has been extended to using alternative base polymers with better resistance to strong acidic, alkaline, and oxidizing environments due to their high hydrophobicity, good chemical resistance, and greater thermal and mechanical properties.

A literature survey indicated that several different alternative base polymers, other than PVC and CTA, have been studied for their suitability as base polymers in PIMs. Furthermore, the stability during applications has also been examined and compared to the PIMs made of PVC or CTA. These alternative base polymers range from non-conventional linear homopolymers, copolymers to cross-linking polymers. However, to the best of our knowledge, a review summarizes alternative base polymers, and their application was not found in the literature. Thus, the present study summarizes the current literature, focusing on those proposing alternative base polymers in the fabrication of PIMs and their application to separate organic and inorganic species. In addition, more emphasis is given to the composition and fabrication process and application of the PIMs. Finally, the performance of the PIMs with the alternative base polymers in terms of extraction rate and long-term stability is presented and compared to the PIMs fabricated using the corresponding common base polymers.

\section{- LIMITATIONS OF PIMS PREPARED USING COMMON BASE POLYMERS (PVC AND CTA)}

In the past several years, CTA and PVC have been the base polymers of choice for the fabrication of PIMs as they are generally compatible with most of the commonly used liquid extractants such as Aliquat 336 and D2EHPA. Moreover, CTA and PVC are easy to handle, readily available, and have been previously well 
studied and used as polymeric support in various other applications such as food packaging, thin-film, reverse osmosis, and filtration membrane. CTA is a highly polar polymer due to hydroxyl and acetyl groups, forming highly orientated hydrogen bonding. Moreover, CTA is a highly crystalline polymer that provides excellent mechanical strength for the PIM. Lee et al. utilized CTAbased PIMs containing lipophilic acyclic polyether dicarboxylic acid as the carrier and NPOE as the plasticizer for the extraction and transport of $\mathrm{Pb}$ (II). The authors indicated that when using $0.1 \mathrm{~mol} \mathrm{~L}^{-1} \mathrm{HNO}_{3}$ as the receiving solution and the feed phase buffered at $\mathrm{pH}$ 5.5, the CTA-based PIMs can be used successively for transport of $\mathrm{Pb}(\mathrm{II})$ over 10 days without losing its performance in terms of the $\mathrm{Pb}(\mathrm{II})$ transport flux [30].

Likewise, Kebiche-Senhadji et al. indicated that a CTA-based PIMs containing D2EHPA could be used successively for a complete transport of $\mathrm{Cd}(\mathrm{II})$ from a neutral feed solution containing $30 \mathrm{mg} \mathrm{L}^{-1} \mathrm{Cd}(\mathrm{II})$ (in $0.1 \mathrm{~mol} \mathrm{~L} \mathrm{~L}^{-1} \mathrm{NaNO}_{3}$ ) into a receiving solution containing $0.1 \mathrm{~mol} \mathrm{~L}^{-1} \mathrm{HNO}_{3}$ for 12 cycles [31]. This research indicated the excellent performance and stability of CTA-based PIMs in a neutral and slightly acidic aqueous environment. However, excellent stability and performance were not observed when highly acidic or alkaline feed or receiving phases were used in the transport experiment using CTA-based PIMs. Research by Kaya et al. found that the performance of CTA-based PIMs containing calyx [4] arene extractant for the removal of $\mathrm{Cr}(\mathrm{VI})$ decreased to $60 \%$ after 10 cycles $(6 \mathrm{~h}$ per cycle) [32]. The transport was conducted using a $0.2 \mathrm{mmol} \mathrm{L}^{-1} \mathrm{~K}_{2} \mathrm{Cr}_{2} \mathrm{O}_{7}$ in $0.1 \mathrm{~mol} \mathrm{~L}^{-1} \mathrm{HCl}$ feed phase and an acetic acid/ammonium acetate buffer $\mathrm{pH} 5$ receiving phase. Similarly, Kebiche-Senhadji et al. found that a CTA-based PIMs containing Aliquat 336 as the extractant and NPOE as the plasticizer lost about $42 \%$ of its efficiency when used consecutively for the transport of $\mathrm{Cr}(\mathrm{VI})\left(10 \mathrm{mg} \mathrm{L}^{-1} \mathrm{pH} 1.2\right.$ in sulfate) to $0.1 \mathrm{~mol} \mathrm{~L}^{-1} \mathrm{NaOH}$ receiving solution [33]. Ghaderi et al. reported approximately $20 \%$ mass loss of the CTA-based PIM containing tri-n-butyl phosphate (TBP) after 2-day continuous immersion in $0.3 \mathrm{~mol} \mathrm{~L}^{-1} \mathrm{HCl}$ [34]. It was revealed that the deterioration in the performance of
CTA-based PIM was due to the loss of carrier into the aqueous feed or receiving phase during the transport period, which could be attributed to the hydrophilicity nature of CTA and the water solubility of the liquid extractant [4]. Moreover, the hydrolysis of the ester linkage in the cellulose backbone, particularly in a highly acidic or alkaline environment, could damage the polymeric backbone and thus affects its compatibility with the liquid extractant [35].

In contrast to CTA, PVC, which contains $\mathrm{C}-\mathrm{Cl}$ bonds, is a relatively polar and amorphous polymer with a low degree of crystallinity. With a glass temperature of $80^{\circ} \mathrm{C}$, the thin film made by casting PVC is highly rigid by nature. Thus, using a plasticizing agent is sometimes necessary if the liquid extractant is without plasticizing properties [4]. However, the main drawback of PIMs made of PVC is related to PVC's inherent properties, which undergo the dehydrochlorination process under alkaline conditions. This unwanted reaction results in hydrochloride removal from the PVC polymer and thus changing the PVC structure serving as the polymeric backbone of the PIMs that is generally indicated by the change of PVC thin film into black color [36]. This change ultimately affects the compatibility between the polymeric structure and the liquid phase of the PIMs.

Unlike CTA, PVC is more resistant to acids, salts, bases, fats, and alcohols, making it another base polymer of choice used in fabricating PIMs for a wide variety of applications. However, research indicated the instability of PVC-based PIMs similar to what has been observed in CTA-based PIMs. A study by Argiropoulos et al. showed a considerable loss of Aliquat 336 extractant (30-40\%) from a PVC-based PIMs when the PIMs were continuously immersed in deionized water for 10 days. This problem could be attributed to the high solubility of Aliquat 336 in a neutral aqueous solution. However, a minimum loss of Aliquat 336 (2.5\%) was observed when the PIMs with the same composition were submerged in a $2.5 \mathrm{~mol} \mathrm{~L}^{-1} \mathrm{HCl}$ solution [37]. This fact indicated that the solubility of Aliquat 336 in the aqueous solution was $\mathrm{pH}$-dependent and was very low in highly acidic aqueous solution, about $0.08 \mathrm{~g} / 100 \mathrm{~mL}$ in a $2 \mathrm{~mol} \mathrm{~L}^{-1}$ $\mathrm{HCl}$ solution at room temperature [38]. Zhang et al. 
utilized a PVC-based PIMs containing tributylphosphate (TBP) $/ \mathrm{FeCl}_{3}$ as the extractant and revealed a $40 \%$ decrease in the extraction ratio of $\mathrm{Li}(\mathrm{I})$ after the third cycle due to the considerable extractant loss [39]. Kiswandono et al. observed the same problem of extractant loss when studying the transport of phenol using PVC-based PIMs containing copoly(eugenol-divinylbenzene) (DVB) as the extractant. The research undertaken indicated that the ultimate lifetime of PVC PIMs containing such extractant for the continuous transport of phenol from $60 \mathrm{mg} \mathrm{L}^{-1}$ phenol as the feed phase and $0.25 \mathrm{~mol} \mathrm{~L}^{-1} \mathrm{NaOH}$ as the stripping solution was 7 days. However, the lifetime of PIMs with such composition can be significantly extended to 62 days by adding $\mathrm{NaNO}_{3}$ into the feed phase $(0.1 \mathrm{~mol}$ $\left.\mathrm{L}^{-1}\right)$. This lifetime improvement could be due to the salting-out effect that the Aliquat 336 solubility decreases in solution with a high concentration of salt [40].

\section{- PIMS PREPARED USING ALTERNATIVE NON- CONVENTIONAL LINEAR HOMOPOLYMERS}

Several types of non-conventional linear homopolymers have been examined for their suitability, compatibility, and stability as a polymeric backbone of PIM. The details of PIM components, fabrication method, and application are summarized in Table 1. Gardner et al. studied the suitability and durability of several cellulose derivative polymers such as CAP, CAB, and CTB in fabricating PIMs containing bis-tert-butylcyclohexano18-crown- 6 for the transport of $\mathrm{K}(\mathrm{I})$ ions. The proposed cellulose derivative polymers contain bulkier groups (i.e., propionate, butyrate, and tributyrate) as substitutions of the acetate groups, which were expected to increase PIM performance in terms of extraction rate and durability under highly acidic and alkaline environments [35]. The research demonstrated that the ion transport represented by $\mathrm{K}(\mathrm{I})$ flux decreased as the alkyl chain lengths increased, which could be ascribed to the increased steric hindrance as the alkyl chain length increased. However, this was compensated by the increase in the durability of PIMs prepared using the proposed cellulose derivatives compared to the CTA-based PIMs when used in a highly acidic and alkaline environment. In particular, higher resistance to CTA hydrolysis under extreme conditions was observed when alkyl chain length increased, which could also be attributed to the increased steric interactions near the ester hydrolysis sites, preventing hydrolysis. Thus, in the long-term use in a highly acidic and alkaline environment, PIMs prepared using cellulose derivate polymer with moderate alkyl group can provide a reasonable transport rate while maintaining long-term stability.

Kunene et al. proposed using polysulfone (PSF) as the polymeric support in fabricating PIMs containing Aliquat 336 as the extractant. The performance of PSFbased PIMs was examined in terms of extraction rate and stability under a highly acidic and alkaline environment and compared to PIMs with the same composition prepared using PVC base polymer [41]. The results demonstrated that the transport performance of the PSF-based PIMs at its optimum composition (40 wt $\%$ PSF and $60 \mathrm{wt} \%$ Aliquat 336) represented by $\mathrm{Cr}(\mathrm{VI})$ flux was one-third lower than that of the optimum PVC-based PIMs (60 wt\% PVC and 40 wt $\%$ Aliquat 336). Furthermore, the lower flux was associated with, the less hydrophilicity of PSF membrane than the PVC-based PIMs (contact angle PSF $>$ contact angle PVC), thus resulting in higher permeability of PVC than the PSF-based PIMs. However, as expected, the stability study suggested that the PSF-based PIMs showed higher stability compared to the PVC-based PIMs, represented as the lower PIM weight loss of PSF-based PIMs compared to that of the PVC-based PIMs in both acidic $\left(1 \mathrm{~mol} \mathrm{~L}^{-1} \mathrm{HNO}_{3}\right)$ and alkaline $\left(0.05 \mathrm{~mol} \mathrm{~L}^{-1} \mathrm{NaOH}\right)$ environment. It was observed that in both acidic and alkaline environments, PSF-based PIMs exhibited superior stability in comparison to the PVC-based PIMs. Notably, the PVCbased PIM color conversion to black was observed under the base environment after the transport experiment, indicating the PVC polymer's dehydrochlorination [36]. The main reason for the superior stability of PSF-based PIMs was due to the presence of aromatic groups and sulfonyl groups which are not decomposed by bases. The superior stability of PSF-based PIMs, particularly under base environment, offers the possibility for its potential application, which requires basic conditions. 
Table 1. Summary of PIMs prepared using non-conventional linear homopolymers and their applications

\begin{tabular}{|c|c|c|c|c|}
\hline $\begin{array}{l}\text { Non-conventional linear } \\
\text { homopolymers }\end{array}$ & Extractant & Plasticizer/Modifier & Analyte & Ref. \\
\hline CAP, САВ, СТВ & $\begin{array}{l}\text { Bis-tert-butylcyclohexano- } \\
\text { 18-crown-6 }\end{array}$ & - & $\mathrm{K}(\mathrm{I})$ & [35] \\
\hline PVDF & Cyphos IL 104 & {$[\mathrm{Cnmim}][\mathrm{PF} 6]$ or $[\mathrm{BF} 4](\mathrm{n}=4,8)$} & $\mathrm{Cr}(\mathrm{VI})$ & {$[52]$} \\
\hline PVDF & {$[\mathrm{A} 336][\mathrm{P} 507]$} & - & $\mathrm{Lu}(\mathrm{III})$ & {$[24]$} \\
\hline A mixture of PVDF and CTA & D2EHPA & TEHP & $\mathrm{Ni}(\mathrm{II}), \mathrm{Zn}(\mathrm{II})$ and $\mathrm{Pb}(\mathrm{II})$ & [53] \\
\hline TPU, PCL & Aliquat-336 & - & $\mathrm{Cr}(\mathrm{VI})$ & [26] \\
\hline PVDF & {$[\mathrm{A} 336][\mathrm{SCN}]$} & NPOE & $\mathrm{Au}(\mathrm{I})$ & {$[44]$} \\
\hline PVDF & NTA & - & $\mathrm{Cr}(\mathrm{VI})$ and $\mathrm{Ni}(\mathrm{II})$ & [48] \\
\hline PVDF & P227 & - & $\mathrm{Lu}(\mathrm{III})$ & {$[50]$} \\
\hline PVDF & $\mathrm{P} 227$ & - & $\mathrm{Lu}(\mathrm{III}), \mathrm{La}(\mathrm{III})$ and $\mathrm{Sm}(\mathrm{III})$ & [51] \\
\hline PSF & Aliquat 336 & - & $\mathrm{Cr}(\mathrm{VI})$ & [41] \\
\hline $\begin{array}{l}\text { A mixture of CTA and PMMA } \\
\text { A mixture of PVC and PMMA }\end{array}$ & & NPOE & $\mathrm{Pb}(\mathrm{II})$ & [54] \\
\hline PVDF & Aliquat 336 & NPOE & $\mathrm{Cr}(\mathrm{VI})$ & [47] \\
\hline PVDF & {$[\mathrm{A} 336][\mathrm{SCN}]$} & NPOE & $\mathrm{Au}(\mathrm{I})$ & [45] \\
\hline PVDF & Cyphos IL 104 & - & $\mathrm{Lu}(\mathrm{III})$ and $\mathrm{Yb}(\mathrm{III})$ & [55] \\
\hline PVDF & D2EHPA & - & $\mathrm{Zn}(\mathrm{II})$ & [49] \\
\hline
\end{tabular}

CAP: cellulose acetate propionate, CAB: cellulose acetate butyrate, CTB: cellulose tributyrate, TPU: polyurethane, PCL: poli $\varepsilon$-caprolactone, PVDF: polyvinylidene fluoride, PSF: polysulfone, PMMA: polymethyl methacrylate, Aliquat ${ }^{\circ}$ 336: trioctylmethylammonium chloride, [A336][SCN]: trioctylmethylammonium thiocyanate, Cyphos IL 104: phosphonium IL trihexyl(tetradecyl)phosphonium bis(2,4,4trimethylpentyl)phosphinate, [A336][P507]: bifunctional ionic liquid extractant [tricaprylmethylammonium][di(2ethylhexyl)orthophosphinate], D2EHPA: di-(2-ethylhexyl) phosphoric acid, NTA: nitrilotriacetic acid, P227: di(2-ethylhexyl) phosphinic acid, [Cnmim][PF6] or [BF4] $(\mathrm{n}=4,8)$ : 1-alkyl-3-methylimidazolium hexafluorophosphate or tetrafluoroborate, TEHP: tris(2-ethylhexyl) phosphate, NPOE: 2-nitrophenyl octylether

More recently, the use of PVDF as the base polymer in PIM fabrication has gained increasing attention due to its outstanding properties such as good chemical resistance, high mechanical strength, and thermal stability, and high hydrophobicity compared to other commercialized polymeric materials [1]. PVDF polymer is highly resistant to acidic, alkaline, or strong oxidizing material [42]. The PVDF-based PIMs reported in the literature can be fabricated using two different techniques, namely solvent evaporation, and phase inversion. The solvent evaporation from the homogenous PIM mixture can be done at room temperature or induced by heating. The phase inversion technique involves immersing the nascent PIM mixture in an immiscible solvent such as water to remove the typical organic solvent used to dissolve the PIM components. The first PVDF-based PIM was introduced by Guo et al. in 2011 for the transport of $\mathrm{Cr}(\mathrm{VI})$, with the liquid phase of the
PIMs composed of Cyphos IL 104 as the extractant and $\left[\mathrm{C}_{8} \mathrm{mim}\right]\left[\mathrm{BF}_{4}\right]$ as the plasticizer. The fabricated PIMs were examined for their performance and stability when transporting $\mathrm{Cr}(\mathrm{VI})$ from a feed phase containing $100 \mathrm{mg} \mathrm{L}^{-1} \mathrm{Cr}(\mathrm{VI})$ in a $0.10 \mathrm{~mol} \mathrm{~L}^{-1} \mathrm{HCl}$ into a stripping phase containing $0.20 \mathrm{~mol} \mathrm{~L}^{-1} \mathrm{NaOH}$. Under the optimum conditions, it was revealed that the PIMs could be reused nine times with a $31 \%$ decrease in permeability (P) after the $9^{\text {th }}$ cycle. This finding indicated the superior stability of the PVDF-based PIMs under an acidic and alkaline environment compared to PIMs composed of CTA, Aliquat 336, and NPOE, whose permeability was decreased by $67 \%$ after the $6^{\text {th }}$ cycle [43]. Chen and Chen further expanded the use of PVDF-based PIMs containing ionic liquid [A336][P507] as the extractant for the separation and pre-concentration of rare earth lutetium $(\mathrm{Lu}(\mathrm{III}))$ [24]. The PIMs were fabricated using a phase inversion method, and the separation of 
lutetium was carried out using a transport cell containing $7.5 \times 10^{-4} \mathrm{~mol} \mathrm{~L}^{-1} \mathrm{LuCl}_{3}, \mathrm{pH} 2.84$ as the feed and $1.0 \mathrm{~mol} \mathrm{~L}^{-1}$ $\mathrm{HCl}$ as the stripping solution. This experiment, performed under $450 \mathrm{rpm}$ stirring speed at $303 \mathrm{~K}$, indicating that the initial flux was stable after ten cycles ( $4 \mathrm{~h}$ per cycle), further demonstrating the high stability and durability of PVDF-based PIMs when used continuously under a highly acidic environment.

In a more recent study, Wang et al. have successfully employed PVDF-based PIMs for the simultaneous extraction and recovery of $\mathrm{Au}(\mathrm{I})$ from a highly alkaline solution [44]. The PIMs were prepared using a thermally induced phase separation, and the optimum PIM composition was composed of 50\% PVDF, $40 \%$ [A336][SCN] as the extractant, and 10\% NPOE as the plasticizer. Under the optimum condition, $98 \% \mathrm{Au}(\mathrm{I}) \mathrm{can}$ be transported from the feed solution containing $0.254 \mathrm{mmol} \mathrm{L}^{-1} \mathrm{Au}(\mathrm{I})$ in a $0.2 \mathrm{~mol} \mathrm{~L}^{-1} \mathrm{NaCl}, \mathrm{pH} 10.50$ into the stripping solution of $3.0 \mathrm{~mol} \mathrm{~L}^{-1} \mathrm{KSCN} \mathrm{pH} \mathrm{10.50.} \mathrm{The}$ stability study indicated that PIMs with the composition mentioned above could be reused ten times for a continuous extraction and recovery of $\mathrm{Au}(\mathrm{I})$ with a slight decrease to $82 \%$ and $78.4 \%$ extraction of $\mathrm{Au}(\mathrm{I})$ after $9^{\text {th }}$ and $10^{\text {th }}$ cycles ( $24 \mathrm{~h}$ per cycle), respectively. A PIM TGA analysis before and after the $10^{\text {th }}$ transport cycle confirmed the liquid-phase reduction of the PIM from $49.4 \mathrm{wt} \%$ (fresh PIM) to $39.8 \mathrm{wt} \%$ (after the $10^{\text {th }}$ cycle) [44]. The same group further improved the transport rate of $\mathrm{Au}(\mathrm{I})$ using PVDF PIMs with the same composition by using an in-situ electrodeposition technique [45]. The authors demonstrated that one complete transport cycle of $\mathrm{Au}(\mathrm{I})$ could be reduced from $24 \mathrm{~h}$ to $12 \mathrm{~h}$, making it possible to extend the lifetime of PIMs with the same components mentioned above. It was found that by applying a constant voltage of $1.50 \mathrm{~V}$ to the stripping solution, the permeability coefficient of $\mathrm{Au}(\mathrm{I})$ can be improved from $9.25 \times 10^{-6} \mathrm{~m} / \mathrm{s}$ (with no voltage) to 21.5 $\times 10^{-6} \mathrm{~m} / \mathrm{s}$ (with voltage). The stability study revealed the superior extraction and recovery of the PIM with $92.4 \%$ recovery of $\mathrm{Au}(\mathrm{I})$ after the $10^{\text {th }}$ cycle [45].

As the most selected base polymer, PVDF has also been compatible with other extractants ranging from ionic liquid to cationic and anionic exchangers, and their stability has also been tested under different environmental conditions (i.e., acidic, alkaline, or neutral). These extractants include Aliquat 336 for removal of $\mathrm{As}(\mathrm{V})$ [46] and transport of $\mathrm{Cr}(\mathrm{VI})$ [47], NTA for extraction and recovery of $\mathrm{Cr}(\mathrm{VI})$ and $\mathrm{Ni}(\mathrm{II})$ ions [48], D2EHPA for extraction of $\mathrm{Zn}$ (II) [49], and P227 for transport of Lu(III) [50-51].

\section{- PIMS PREPARED USING CO-POLYMERS}

In recent research, copolymers have been used as the base polymer to improve the performance of PIMs, in addition to the non-conventional linear homopolymers. As the name suggested, a copolymer is a polymer formed when more than one type of monomer is linked together in the same polymeric chain instead of a homopolymer that involves a chemically linked of only a single monomer. This type of polymer is obtained by copolymerization to form an interchangeable arrangement of monomers in the fabricated polymers. The formation of the copolymer is intended to improve the performance, stability, durability, and resistance to certain conditions by combining the properties of the constituent monomers of the copolymer. The literature study has indicated that PVDF-HFP is the most widely used copolymer in the fabrication of PIMs in the past several years. The growing interest in using PVDF-HFP for PIM fabrication is due to its high hydrophobicity, thermal stability, mechanical strength, better solubility in THF used for preparing PIMs casting solution, and excellent resistance to a wide range of chemicals [42,5657]. In addition, due to its relatively low glass transition temperature $\left(40^{\circ} \mathrm{C}\right)$, PVDF-HFP presents in a rubbery state at room temperature suitable for PIM fabrication. These excellent properties have made it popular in various applications such as microfiltration membrane [58], support for SLMs [59] and hollow fiber membrane [46], and matrix for the polymer gel electrolyte of lithium-ion batteries [60-61]. These have also made them favorable candidates as the base polymer in the PIM fabrication. The details of PIM components, method of fabrication, and application are summarized in Table 2.

The first copolymer used for PIM fabrication was reported by Guo et al. to transport $\mathrm{Cr}(\mathrm{VI})$ [62]. The 
proposed PIMs were made by phase inversion method and was composed of PVDF-TFE as the base polymer, bifunctional ionic liquid ([A336][C272], [A336][P204], [A336][P507]) as the extractants and [C8mim][PF6] or [BF4] as the plasticizer. The morphology study showed that the addition of bifunctional IL to the PVDF-TFE polymer increases the surface unevenness and the hydrophobicity of the PIMs, indicated by a significant increase in the contact angle of the PIMs. Such increases would thus enlarge the effective contact area of the membrane. The transport experiments demonstrated that the permeability of $\mathrm{Cr}(\mathrm{VI})$ across the PVDF-TFE-based PIMs containing the proposed extractants were all higher than the one containing Cyphos IL 104. It was further indicated that the maximum initial flux of $\mathrm{Cr}(\mathrm{VI})$ (40.08 $\mu \mathrm{mol} \mathrm{m} \mathrm{m}^{-2} \mathrm{~s}^{-1}$ ) could be achieved when using the [A336][P204] as the extractant and when $0.20 \mathrm{~mol} \mathrm{~L}^{-1}$
$\mathrm{HCl}$ and $0.05 \mathrm{~mol} \mathrm{~L}^{-1} \mathrm{NaOH}$ were used respectively as feed and stripping phases. However, the PVDF-TFEbased PIMs' stability with [A336][P204] was lower than the corresponding PIMs containing Cyphos IL 104. It was observed that the permeability of PVDF-TFE PIMs containing [A336][P204] decreased about $41 \%$ after continuously being used for six cycles. This drop was associated with partial decomposition of the $\mathrm{PIM} \mathrm{BF}_{4}^{-}$ and the oxidation of the PIM material by $\mathrm{Cr}(\mathrm{VI})$ [62].

As the most commonly used copolymers in the fabrication of PIMs, PVDF-HFP has been reported for extractions and transports of various chemical species. O'Bryan et al. were the first to use PVDF-HFP base polymer to fabricate PIMs and successfully applied them for the extraction and back-extraction of $\mathrm{SCN}^{-}$. The authors showed that the performance of PVDF-HFPbased PIMs was significantly better than the

Table 2. Summary of PIMs prepared using copolymers and their applications

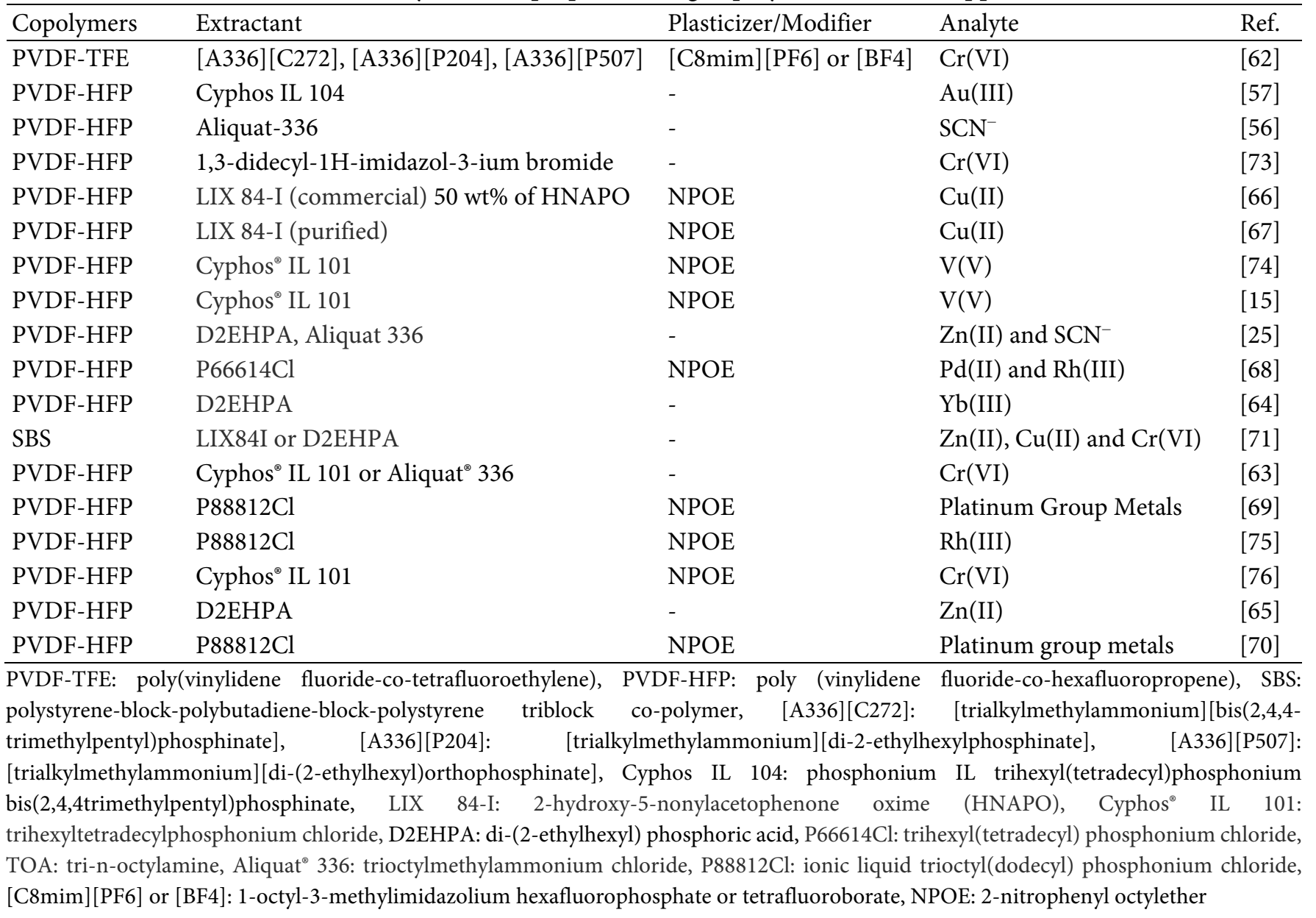


corresponding PIMs prepared using PVC base polymer, represented by $9.29 \pm 0.64 \times 10^{-6} \mathrm{~mol}^{-2} \mathrm{~s}^{-1}$ initial flux of $\mathrm{SCN}^{-}$for PVDF-HFP-based PIMs as opposed to $5.47 \pm$ $0.69 \times 10^{-7} \mathrm{~mol}^{-2} \mathrm{~s}^{-1}$ the case in PVC-based PIMs. This report indicates 17 times higher initial flux of PVDF-HFP PIMs than that of the PVC PIMs, showing superior performance of PVDF-HFP-based PIMs. Likewise, the authors showed that the stability performance of PVDFHFP-based PIMs was significantly better than that of the PVC-based PIMs. The PVDF-HFP-based PIMs were described to withstand a continuous extraction and backextraction of $\mathrm{SCN}^{-}$for eleven cycles with less than $5 \%$ loss in PIMs liquid phase instead of the PVC-based PIMs, which experienced the same loss in its $7^{\text {th }}$ cycle. The authors attributed the outstanding performance of the PVDF-HFP-based PIMs to the rougher surface compared to the corresponding PVC-based PIMs, leading to a larger effective contact area [56].

The superiority of PVDF-HFP-based PIMs has also been shown to extract and transport metal ions in highly acidic conditions. Yaftian et al. demonstrated that PVDFHFP-based PIMs (35 wt\% Cyphos ${ }^{\otimes}$ IL 101, 10 wt\% NPOE, $55 \mathrm{wt} \%$ PVDF-HFP) could be used to continuously extract $\mathrm{V}(\mathrm{V})$ from a $50 \mathrm{~mL}$ of $50 \mathrm{mg} \mathrm{L}^{-1} \mathrm{~V}(\mathrm{~V})$ in $0.2 \mathrm{~mol} \mathrm{~L}^{-1}$ sulfate pH 2.3 and back-extract into $50 \mathrm{~mL}$ of $6 \mathrm{~mol} \mathrm{~L}^{-1} \mathrm{H}_{2} \mathrm{SO}_{4}$. The stability study indicated that the PVDF-HFP-based PIMs could be used consecutively for five cycles without losing their extraction capacity. The authors attributed the superior properties of PVDF-HFP base polymer and the lipophilicity of the Cyphos IL 101 extractant. Bonggotgetsakul et al. demonstrated that PVDF-HFPbased PIMs containing Cyphos IL 104 recover gold from aqua regia digested electronic waste [57]. The PIMs was composed of 70\% PVDF-HFP and 30\% Cyphos IL 104 and were prepared by a solvent evaporation method using a homemade casting knife. The stability study of the PIMs for five cycles of extraction and back-extraction process under the optimum conditions indicated that the PIMs with such composition could be consecutively used for four cycles without losing their extraction performance. However, a slight extraction performance decreased after the $5^{\text {th }}$ cycle was due to approximately $3 \%$ of PIM's mass loss. Despite the slight deterioration in the PIM's performance after the $4^{\text {th }}$ cycle, these PVDF-HFP-based PIMs have shown promising performance for separating gold under highly acidic conditions. The superior stability of PVDF-HFP-based PIMs under highly acidic conditions has also been demonstrated for the extraction and separation of other chemical species such as $\mathrm{Cr}(\mathrm{VI})$ [63], Yb(III) [64], Zn(II) [25,65]. While PVDF-HFPbased PIMs for $\mathrm{Cr}(\mathrm{VI})$ extraction were composed of an ionic liquid such as 1,3-didecyl-1H-imidazol-3-ium bromide and Cyphos IL101, those for the extractions and separations of $\mathrm{Zn}(\mathrm{II})$ and $\mathrm{Yb}(\mathrm{III})$ were composed of D2EHPA as the extractant.

Some authors have reported using PVDF-HFPbased PIMs for extraction and back-extraction of specific metal ions under alkaline conditions. For example, Wang et al. demonstrated a successful separation of $\mathrm{Cu}(\mathrm{II})$ from its ammonium sulfate/ammonia solutions ( $\mathrm{pH}$ 8.5) using PVDF-HFP PIMs containing LIX 84I as the extractant [66]. The authors compared the performances of the PVDF-HFP PIMs to the corresponding PIMs made of PVC or CTA base polymers and revealed that the PVC- and CTAbased PIMs exhibited an oily surface after the extraction, which indicated the loss of the PIM's liquid phase. PVDF-HFP-based PIMs, on the other hand, were homogenous and with oily free surfaces after the extraction. Furthermore, the authors conducted a stability study using the PVDF-HFP-based PIMs and found that the performance was stable for five cycles when transporting $\mathrm{Cu}(\mathrm{II})$.

Further study indicated that the PIMs with such composition exhibited only $10 \%$ of mass loss after use for a consecutive five cycles [66]. Furthermore, the same authors compared PVDF-HFP-based PIMs containing the commercial LIX 84I to the corresponding PIMs containing purified LIX 84I in terms of $\mathrm{Cu}(\mathrm{II})$ transport and reported these two types of PVDF-HFP-based PIMs exhibited a similar extraction rate of $\mathrm{Cu}(\mathrm{II})$. Interestingly, the PVDF-HFP-based PIM with commercial LIX 84I exhibited slightly higher transport efficiency and stability. Thus, the research indicated that the LIX 84I could be used directly in the PIM fabrication without any complex purification procedure [67]. 
In more recent research, PVDF-HFP-based PIMs have also been produced and utilized for the extraction and separation of platinum group metals (PGMs), which involve platinum $(\mathrm{Pt})$, palladium $(\mathrm{Pd})$, and rhodium $(\mathrm{Rh})$. A PVDF-HFP-based PIM contained $\mathrm{P} 66614 \mathrm{Cl}$ as the extractant was used for the separations of $\mathrm{Pd}(\mathrm{II})$ and $\mathrm{Rh}$ (III). The stability study indicated that the PIM's Pd(II) recovery factor performance was constant throughout seven operation cycles. A PIM FTIR examination before and after 7-day immersion in $10 \mathrm{~mol} \mathrm{~L}^{-1} \mathrm{HCl}$ exhibited the characteristic functional groups of PVDF-HFP and $\mathrm{P} 66614 \mathrm{Cl}$ in the PIM before and after immersion. These spectra indicated the absence of PIM structural changes before and after immersion in a highly acidic solution, which also revealed the stable performance of PVDFHFP-based PIMs containing $\mathrm{P} 66614 \mathrm{Cl}$ for the separation of $\mathrm{Pd}(\mathrm{II})$ [68]. In separate research, the same authors reported a selective separation of PGMs using PVDFHFP-based PIMs containing a newly synthesized P88812Cl ionic liquid as the extractant [69]. The separation of $\mathrm{Pt}(\mathrm{IV}), \mathrm{Pd}(\mathrm{II})$, and $\mathrm{Rh}(\mathrm{III})$ was carried out sequentially by varying the receiving solution used in each step of separation. In the first sequence, the $\mathrm{Pt}(\mathrm{IV})$ was completely and selectively separated from the other PGMs using $0.1 \mathrm{~mol} \mathrm{~L}^{-1} \mathrm{NaClO}_{4}$ in $1 \mathrm{~mol} \mathrm{~L}^{-1} \mathrm{HCl}$ as the receiving solution. In the second sequence, ten $\mathrm{mmol} \mathrm{L}^{-1}$ thiourea and $0.1 \mathrm{~mol} \mathrm{~L}^{-1} \mathrm{KSCN}$ in $1 \mathrm{~mol} \mathrm{~L}^{-1} \mathrm{HCl}$ was used as the receiving phase to selectively separate $\mathrm{Pd}(\mathrm{II})$, leaving the $\mathrm{Rh}$ (III) in the feed solution. A stability study indicated that a PVDF-HFP-based PIMs containing the proposed ionic liquid could be continuously used over a 4-cycle sequential separation of PGMs (7 days per cycle), making it to total use for four weeks. It was observed that the recovery factor of $\mathrm{Pt}(\mathrm{IV})$ decreased by $7 \%$, while that of the $\mathrm{Pd}(\mathrm{II})$ remained stable after four cycles of sequential operations. This superior performance of PVDF-HFP-based PIMs could be attributed to a minimal loss of the liquid phase during its sequential operation, indicated by a $6.2 \pm 0.5 \mathrm{mg}$ loss from the initial PIM's mass of $121 \pm 1 \mathrm{mg}$ [69]. Moreover, the authors had successfully demonstrated the efficiency of PVDF-HFP-based PIMs containing $\mathrm{P} 88812 \mathrm{Cl}$ ionic liquid as the extractant for separating PGMs from spent automotive catalysts [70].
The use of an SBS copolymer for the fabrication of PIMs for the extraction of $\mathrm{Zn}$ (II), $\mathrm{Cu}$ (II), and $\mathrm{Cr}(\mathrm{VI})$ had also been reported [71]. Unlike, PVDF-HFP which consists of only two monomers, SBS consists of three blocks of copolymers, including polystyrene, polybutadiene, and polystyrene. SBS is an accessible thermoplastic elastomer that poses the excellent properties required for use as PIM's base polymers, including high flexibility (over 1000\% stretching ability) and mechanical strength (over $10 \mathrm{MPa}$ tensile strength), and superior resistance to acids and bases [72]. Furthermore, SBS is cheaper than PVDF, the most common copolymer used as the base polymers in producing highly stable PIMs. Based on their compatibility study, SBS copolymer was found to be compatible with D2EHPA, LIX 84I, and TOA. However, the authors indicated that when the PIMs were respectively used for the extraction of $\mathrm{Zn}$ (II), $\mathrm{Cu}(\mathrm{II})$, and $\mathrm{Cr}(\mathrm{VI})$, the PIM containing TOA showed a poor performance. Thus, the extraction experiments were carried out only using SBS-based PIMs containing D2EHPA to extract $\mathrm{Zn}$ (II) and LIX 84I to extract $\mathrm{Cu}(\mathrm{II})$. The research indicated that although the SBS PIMs containing D2EHPA extracted $\mathrm{Zn}$ (II) at a slower rate, the SBS-based PIMs were superior in the $\mathrm{Zn}$ (II) extracted. Likewise, the authors found that the performance of the SBS-based PIMs containing LIX 84I was superior in terms of the amount of $\mathrm{Cu}$ (II) extraction compared to the corresponding PIMs containing a similar amount of extractant made of PVC, CTA, and PVDF-HFP base polymers. Despite the superior performance in terms of the amount of analyte extracted, the SBS-based PIMs were found to be less stable when compared to other base polymers containing the same extractant, which maybe because of the loss of liquid phase to the aqueous phase during the extraction process. However, the low cost of SBScopolymers may justify using the fabricated PIM in a single run. In this context, a cross-linking of the SBS polymer with another polymer with better properties may be a suitable option to prevent the leaching of extractants during their application. 


\section{- PIMS PREPARED USING CROSS-LINKING POLYMERS}

Crosslinking polymers have also been predominantly studied as promising base polymer candidates in improving the performance of PIMs. Crosslinking polymers involve forming a network between two polymeric structures through either covalent or ionic bonds, which promote a more connecting network to the newly formed polymeric structures. Consequently, in comparison to the constituent polymers, the cross-linking polymers have a more tortuous environment which can curb the mobility of the PIMs' liquid phase and thus preventing the leaching of PIMs' liquid phases into the aqueous solution during their application [77-78]. Therefore, these cross-linking polymers increase the stability of the PIMs if they are to be used in a long-term application. Furthermore, the newly formed network among the constituent polymers can also promote changes in other physical or chemical properties, such as increasing the dimensional, thermal, and mechanical stability of PIMs suitable for their longterm application [79]. In general, the photo-induced polymerization technique has been extensively used in the fabrication of PIMs due to the rapid and efficient polymer fabrication process instead of the more traditional approach based on thermal manipulation, which may damage the constituent polymeric structures. This process essentially requires three main components: a photoinitiator, a reactive end-group prepolymer, and mono or multifunctional monomer capable of accelerating rapid and extensive polymerization. Photoinitiators play a key role in absorbing light which initiates the generation of reactive radicals and/or cations to allow the polymerization reaction. The chemical structure of reactive end-group prepolymers, commonly known as 3-D backbone network telechelic oligomer, critically influences its physical properties upon UV exposure. The functionality, in principle, acts as the crosslinking agent influencing the kinetics and the properties of the PIMs. These three elements required in the lightdriven polymerization system heavily impact the developed polymer structure characteristics such as stability, permeability, durability, selectivity, and extraction capacity [79-80].

Several reports on using cross-linking base polymer to fabricate PIMs were summarized in Table 3. The first development of cross-linking base polymers to enhance the stability and permeability of PIMs was reported by O'Bryan et al. [81]. The study employed a cross-linked semi-interpenetrating polymer network between PVDF-HFP and PEG-DMA. The use of UV irradiation with 2,2-dimethoxy-2-phenylacetophenone (DMPA) as a photoinitiator was examined in which PVDF-HFP/PEG-DMA cross-linked with 5 to 5 ratios containing $40 \%$ Aliquat 336 extractant displayed a higher initial flux value in transporting $\mathrm{SCN}^{-}$(50-fold higher) compared to that of the PIMs prepared using PVDF-HFP or PVC base polymers. The significant enhancement of transport properties of the developed PVDF-HFP/PEG-DMA cross-linked PIM was associated with the hydrophilic nature of PEG in the fabricated membrane's polymeric structure. The superior stability of the fabricated PVDF-HFP/PEGDMA-based PIMs was also achieved, indicated by a low degree of carrier loss during five consecutive transport cycles of $\mathrm{SCN}^{-}$. Unlike other types of PIMs, the proposed PIMs did not require the use of a plasticizer due to the low glass transition temperature of the PVDF-HFP constituent-based polymer. This potentially reduces PIMs fabrication total cost while offering excellent PIMs performance in terms of transport rate and stability [81].

A novel PIM based on cross-linking base polymer with a suitable extracting agent has been recently proposed by Hoque and co-workers to extract $\mathrm{Zn}$ (II) with a higher transport rate and stability [82]. The suitability of three base polymers (i.e., PVC, CTA, and PVDF-HFP) in the formation of PIMs using PEG-DMA as the cross-linking polymer and DMPA as the photoinitiator were investigated. The results indicated that the PVDF-HFP and CTA were compatible with PEGDMA, unlike the PVC polymer, thus forming successful homogenous cross-linked PIMs. Furthermore, an extraction study indicated that CTA/PEG-DMA crosslinked PIMs containing D2EHPA had greater extraction capacity than PVDF-HFP/PEG-DMA cross-linked PIMs 
Table 3. Summary of PIMs prepared using cross-linking-polymers and their applications

\begin{tabular}{|c|c|c|c|c|c|}
\hline Polymers & Extractant & Plasticizer/Modifier & Cross-linker/technique & Analyte & Ref. \\
\hline PVDF-HFP/PEG-DMA & Aliquat 336 & - & $\begin{array}{l}\text { DMPA } \\
\text { UV irradiation }\end{array}$ & $\mathrm{SCN}^{-}$ & [81] \\
\hline $\begin{array}{l}\text { GPO synthesized from } \\
\text { epoxidized castor oil/CA }\end{array}$ & B18C6 & BMIMCl & $\begin{array}{l}\text { IPDI } \\
\text { Heat }\left(60^{\circ} \mathrm{C}\right)\end{array}$ & $\mathrm{Ca}(\mathrm{II})$ & [85] \\
\hline CTA/PEG-DMA & D2EHPA & NPOE & $\begin{array}{l}\text { DMPA } \\
\text { UV Irradiation }\end{array}$ & $\mathrm{Zn}(\mathrm{II})$ & [82] \\
\hline $\begin{array}{l}\text { GPO synthesized from } \\
\text { epoxidized castor oil/CA }\end{array}$ & $12 \mathrm{C} 4$ & BMIMCl & $\begin{array}{l}\text { IPDI } \\
\text { Heat }\left(60^{\circ} \mathrm{C}\right)\end{array}$ & $\operatorname{Li}(\mathrm{I})$ & [86] \\
\hline $\begin{array}{l}\text { PVC, CTA, PVDF-HFP and } \\
\text { PEGDMA, PEGDVE, NEM }\end{array}$ & $\begin{array}{l}\text { Aliquat } 336 \text { or } \\
\text { D2EHPA }\end{array}$ & NPOE & $\begin{array}{l}\text { TASHFP, TPO or DMPA } \\
\text { UV Irradiation }\end{array}$ & $\mathrm{SCN}^{-}$or $\mathrm{Zn}(\mathrm{II})$ & [83] \\
\hline PVDF-HFP/PEG-DMA & Cyphos IL 104 & - & $\begin{array}{l}\text { DMPA } \\
\text { UV Irradiation }\end{array}$ & $\mathrm{Au}(\mathrm{III})$ & [84] \\
\hline
\end{tabular}

PVDF-HFP: poly (vinylidene fluoride-co-hexafluoropropene), PEG-DMA: poly(ethylene glycol) dimethacrylate, PEG-DVE: poly(ethylene glycol) divinylether, NEM: $N$-ethylmaleimide, GPO: green polyol, CA: cellulose acetate, CTA: cellulose triacetate, Aliquat ${ }^{\oplus}$ 336: trioctylmethylammonium chloride, B18C6: benzo-18-crown-6, D2EHPA: di-(2-ethylhexyl) phosphoric acid, 12C4: 12-Crown-4, Cyphos IL 104: phosphonium IL trihexyl(tetradecyl)phosphonium bis(2,4,4trimethylpentyl)phosphinate, BMIMCl: 1-butyl3methylimidazolium chloride, NPOE: 2-nitrophenyl octylether, IPDI: isophorone isocyanate, DMPA: dimethoxy-2-phenyl acetophenone, TASHFP: triarylsulfonium hexafluorophosphate salts, TPO: triphenylphosphine oxide

or non-cross-linked CTA PIMs. In addition, the crosslinked CTA-based PIMs containing 40 wt\% D2EHPA, 10 wt\% NPOE, and 0.6 wt\% DMPA demonstrated superior stability compared to its non-cross-linked counterparts over 5-cycle extraction and back-extraction experiments (13 h per cycle). The authors attributed this superior stability and higher extraction rate of cross-linked CTAbased PIMs to the higher specific surface area of the PIMs, indicated by a more significant number of shallow voids obtained by AFM (atomic force microscopy) imaging as opposed to that of the non-cross-linked ones [82].

The same group further investigated the potential of producing PIMs using different types of cross-linking polymers with the common base polymers (i.e., PVC, CTA, or PVDF-HFP) using PEG-DMA poly(ethylene glycol) dimethyl acrylate, PEG-DVE poly(ethylene glycol) divinyl ether, and $\mathrm{N}$-ethylmaleimide (NEM) as the cross-linking polymers or monomers and several types of photoinitiator [83]. The research suggested that while the cross-linked PIMs can be formed using each common base polymer, the fabrication procedure (i.e., PIM composition and UVirradiation time) differed from one to another common polymer which revealed different behavior of base polymer, cross-linking polymer/monomer, and a photoinitiator. It was found that the optimum homogenous cross-linking conditions critically depend on the nature of the base polymer backbone incorporated with suitable extractant and the UV-irradiation time. The successfully formed cross-linked PIMs' performance was assessed based on their extraction capacities towards either $\mathrm{SCN}^{-}$or $\mathrm{Zn}$ (II) using Aliquat 336 or D2EHPA as the extractant, respectively. The results obtained were compared to those of the non-cross-linked PIM counterparts, which indicated that among all the successful PIMs, 13 homogenous PIMs exhibited 45\% higher extraction than the non-cross-linked ones. Interestingly, the initial fluxes of the developed crosslinked PIMs demonstrated an increase of 10 times higher than those of non-cross-linked PIM counterparts [83].

Moreover, research on the application of crosslinked PIMs conducted by Hoque and co-workers has been extended to the study of various types of polymers to enhance $\mathrm{Au}(\mathrm{III})$ recovery from electronic waste [84]. They employed Cyphos IL 104 as the extractant, and CTA, PVC, and PVDF-HFP were tested as the base polymers. PEGMA, PEGDVE, and NEM acting as crosslinking agents were also examined, while TASHFP and DMPA were separately used to initiate polymerization 
reactions. They found that the use of both TASHFP and DMPA initiators resulted in homogenous cross-linked PIMs. PVDF-HFP-based cross-linked PIMs exhibited excellent performance in extracting substantial amounts of $\mathrm{Au}(\mathrm{III})$ and increasing extraction rate compared to non-cross-linked PIM counterparts. Notably, Hoque and co-workers reported that the cross-linked PIMs incorporated with Cyphos IL 104 (30 wt\%) as the extractant with the ratio of PVDF-HFP base polymer and PEGDMA cross-linking polymer (6:4) photoinitiated by either DMPA (1 wt\%) or TASHFP 2 (wt\%) showed a two-times faster $\mathrm{Au}(\mathrm{III})$ transport from $2.6 \mathrm{~mol} \mathrm{~L}^{-1} \mathrm{HCl}$ solutions.

Furthermore, the newly developed cross-linked PIMs displayed excellent stability over five consecutive transport experiments. However, it is essential to note that cross-linked PIMs photochemically initiated by TASHFP fully recovered $\mathrm{Au}(\mathrm{III})$ in a specific aqua regia feed solutions with $6 \mathrm{~mol} \mathrm{~L}^{-1}$ acidity. They argued that the outstanding transport performance of the PVDF-HFPbased cross-linked PIMs in comparison to their noncross-linked counterparts was associated with higher surface area being in contact with the solution as suggested by AFM data analysis [84].

Darvishi and co-workers have recently proposed an alternative cross-linked PIM for selective recovery of $\mathrm{Ca}(\mathrm{II})$ from its mixture with $\mathrm{K}(\mathrm{I}), \mathrm{Na}(\mathrm{I})$, and $\mathrm{Mg}(\mathrm{II})$ [85]. The PIMs were made of a cross-linked high-molecularweight green polyol (GPO) as a base polymer, a benzene18crown-6 (B18C6) as a carrier, and 1-Butyl-3methylimidazolium chloride (BMIMCl) as a plasticizer. As the base polymer, GPO was prepared through an epoxidation reaction between castor oil and cellulose acetate, followed by a cross-linking process using isophorene isocyanate as the initiators. The research showed that the PIMs prepared using cross-linked GPO posed higher flux when compared to the PIMs containing the same amount of extractant but with other types of base polymers such as PVC, CTA, and PVDF. Moreover, over ten $\mathrm{Ca}(\mathrm{II})$ transport cycles, the stability test indicated superior stability of the cross-linked PIMs compared to those prepared using PVDF, PVC, and CTA. A 5\% decrease in the $\mathrm{Ca}$ (II) flux across the cross-linked PIMs was observed instead of the 16,15 and $34 \%$ reduction for the PIMs prepared using PVDF, PVC, and CTA polymers, respectively. The authors attributed the better flux and stability cross-linked PIMs to the higher surface roughness [85]. Kazemzadeh and co-workers further utilized PIMs prepared using the same cross-linking polymers with 12C4: 12 -Crown-4 as the extractant for selective separation of $\mathrm{Li}(\mathrm{I})$ from a solution containing other metal ions such as $\mathrm{Na}(\mathrm{I}), \mathrm{K}(\mathrm{I}), \mathrm{Ca}(\mathrm{II})$, and $\mathrm{Mg}(\mathrm{II})$. They demonstrated that higher $\operatorname{Li}(\mathrm{I})$ flux could be obtained using the cross-linked PIMs compared to the same PIMs prepared using the corresponding common base polymers such as PVDF, PVC, and CA [86].

\section{- CONCLUSIONS AND FUTURE PERSPECTIVES}

The present review has summarized the current literature on the improvement of the performance of PIMs with a particular focus on the use of alternative base polymers. These include using non-conventional linear homopolymers, copolymers, and cross-linking polymers to fabricate the new PIMs with superior extraction rate and stability properties. As has been documented, the review has also evaluated and examined the performance of the newly developed PIMs when compared to the PIMs prepared using the common base polymers such as PVC and CTA. The stability of the PIMs for multicycle use under a variety of conditions (i.e., highly acidic and alkaline) has also been highlighted.

While there have been several non-conventional linear homopolymers, the study has indicated that PVDF has been the most commonly selected base polymer for PIM fabrication with a higher extraction rate and stability under highly acidic and alkaline conditions. In addition to its inherent properties, which fulfill the requirement for the polymeric support of the PIMs, PVDF also shows a very strong resistance towards acid, alkaline, and oxidizing agents. As described above, the PVDF-based PIMs demonstrate excellent compatibility with many different extractants such as Cyphos IL 101, Cyphos IL 104, D2EHPA, and Aliquat 336. In most cases, the newly developed PIMs have also demonstrated superior stability under a wide range of extraction conditions, including extreme acidic or alkaline conditions and for various analytes. 
Copolymers have been another alternative base polymer for PIM fabrication due to the favorable properties of polymeric support. Copolymers allow the combination of the properties of two or more constituent monomers, thus providing new polymeric support suitable for the fabrication of highly stable PIMs for longterm use and improving extraction and separation rates. Like the linear homopolymers, PIMs made of copolymers, and different extractants have also been studied. Studies on their extraction rate and stability under different conditions revealed that these types of PIMs are superior compared to their corresponding PIMs prepared using common base polymers. Some authors ascribed this superiority to the increase in the PIM roughness, which results in a higher specific surface area being in contact with the solution and the ability to prevent leaching of liquid phase during their use.

Despite being well studied and applied in various other fields, cross-linking polymers have just been recently introduced and used as base polymers to prepare PIMs. Research undertaken indicated that cross-linking polymers allow combining the properties of two different polymers in a newly formed polymeric network. The cross-linking increases the connecting network within the cross-linked PIMs, resulting in a more tortuous environment than PIMs prepared using non-cross-linked PIMs. This environment can curb the mobility of the liquid phase and prevent its leaching during the application of PIMs, which explains the superior stability of cross-linked PIMs compared to the PIMs prepared using non-cross-linking base polymers. Moreover, the cross-linking between two constituent polymers can also promote changes in other physical or chemical properties, such as increasing the dimensional, thermal, and mechanical stability of PIMs suitable for their long-term application. As has been documented, the PIMs prepared using cross-linking polymers, in most cases, exhibited a higher transport rate and posed more excellent stability when used for multiple cycles.

In general, these new types of base polymers are promising alternatives base polymers for the fabrication of PIMs with high transport rates and more excellent stability. Furthermore, with the increasing use in various applications and its demand to comply with green chemistry to further minimize the use of chemicals, the research on PIMs is expected to grow in the future significantly. Moreover, in the future, large-scale industrial fabrication and application of PIMs may be an interesting topic to explore, involving automatic casting membrane and continuous larger-scale extraction and back-extraction system. Furthermore, the research may also be directed to produce PIMs with a highly stable and greater extraction rate. However, it should also consider an environmentally friendly point of view by using alternative renewable and reusable polymeric materials to minimize the generation of polymer waste.

\section{- AUTHOR CONTRIBUTIONS}

FN formulated the idea, performed the literature survey, and wrote the original article. OTS wrote the original article and revised the manuscript. BH, DT, and MCD revised the manuscript. All authors agreed to the final version of this manuscript.

\section{- REFERENCES}

[1] Almeida, M.I.G.S., Cattrall, R.W., and Kolev, S.D., 2012, Recent trends in extraction and transport of metal ions using polymer inclusion membranes (PIMs), J. Membr. Sci., 415-416, 9-23.

[2] Djunaidi, M.C., Fauzi, H., and Hastuti, R., 2018, Desalination of sea water using polymer inclusion membrane (PIM) with Aliquat 336-TBP (tributhyl phosphate) as carrier compound, MATEC Web Conf., 156, 08004.

[3] Kiswandono, A.A., Siswanta, D., Aprilita, N.H., and Santosa, S.J., 2012, Transport of phenol through inclusion polymer membrane (PIM) using copoly (eugenol-DVB) as membrane carriers, Indones. J. Chem., 12 (2), 105-112.

[4] Nghiem, L.D., Mornane, P., Potter, I.D., Perera, J., Cattrall, R.W., and Kolev, S.D., 2006, Extraction and transport of metal ions and small organic compounds using polymer inclusion membranes (PIMs), J. Membr. Sci., 281 (1-2), 7-41.

[5] Almeida, M.I.G.S., Cattrall, R.W., and Kolev, S.D., 2017, Polymer inclusion membranes (PIMs) in 
chemical analysis - A review, Anal. Chim. Acta, 987, 1-14.

[6] Jha, R., Rao, M.D., Meshram, A., Verma, H.R., and Singh, K.K., 2020, Potential of polymer inclusion membrane process for selective recovery of metal values from waste printed circuit boards: A review, $J$. Cleaner Prod., 265, 121621.

[7] Mwakalesi, A.J., and Potter, I.D., 2020, Removal of picloram herbicide from an aqueous environment using polymer inclusion membranes, J. Environ. Chem. Eng., 8 (5), 103936.

[8] Kuswandi, B., Nitti, F., Almeida, M.I.G.S., and Kolev, S.D., 2020, Water monitoring using polymer inclusion membranes: A review, Environ. Chem. Lett., 18 (1), 129-150.

[9] Almeida, M.I.G.S., Chan, C., Pettigrove, V.J., Cattrall, R.W., and Kolev, S.D., 2014, Development of a passive sampler for Zinc(II) in urban pond waters using a polymer inclusion membrane, Environ. Pollut., 193, 233-239.

[10] Nitti, F., Almeida, M.I.G.S., Morrison, R., Cattrall, R.W., Pettigrove, V.J., Coleman, R.A., and Kolev, S.D., 2018, Development of a portable 3D-printed flow-through passive sampling device free of flow pattern effects, Microchem. J., 143, 359-366.

[11] Nitti, F., 2020, Development of flow-through devices for passive sampling of zinc (II) in aquatic systems free from environmental effects, Dissertation, University of Melbourne, Australia.

[12] Garcia-Rodríguez, A., Fontàs, C., Matamoros, V., Almeida, M.I.G.S., Cattrall, R.W., and Kolev, S.D., 2016, Development of a polymer inclusion membrane-based passive sampler for monitoring of sulfamethoxazole in natural waters. Minimizing the effect of the flow pattern of the aquatic system, Microchem. J., 124, 175-180.

[13] Vera, R., Anticó, E., and Fontàs, C., 2018, The use of a polymer inclusion membrane for arsenate determination in groundwater, Water, 10 (8), 1093.

[14] Zhang, L.L., Cattrall, R.W., and Kolev, S.D., 2011, The use of a polymer inclusion membrane in flow injection analysis for the on-line separation and determination of zinc, Talanta, 84 (5), 1278-1283.
[15] Yaftian, M.R., Almeida, M.I.G.S., Cattrall, R.W., and Kolev, S.D., 2018, Flow injection spectrophotometric determination of $\mathrm{V}(\mathrm{V})$ involving on-line separation using a poly(vinylidene fluoride-co-hexafluoro propylene)-based polymer inclusion membrane, Talanta, 181, 385-391.

[16] Casanueva-Marenco, M.J., Díaz-de-Alba, M.I., Herrera-Armario, A., Galindo-Riaño, M.D., and Granado-Castro, M.D., 2020, Design and optimization of a single-use optical sensor based on a polymer inclusion membrane for zinc determination in drinks, food supplement and foot health care products, Mater. Sci. Eng., C, 110, 110680.

[17] Jayawardane, B.M., Coo, L.D., Cattrall, R.W., and Kolev, S.D., 2013, The use of a polymer inclusion membrane in a paper-based sensor for the selective determination of $\mathrm{Cu}(\mathrm{II})$, Anal. Chim. Acta, 803, 106-112.

[18] Zulkefeli, N.S.W., Weng, S.K., and Abdul Halim, N.S., 2018, Removal of heavy metals by polymer inclusion membranes, Curr. Pollut. Rep., 4 (2), 8492.

[19] Keskin, B., Zeytuncu-Gökoğlu, B., and Koyuncu, I., 2021, Polymer inclusion membrane applications for transport of metal ions: A critical review, Chemosphere, 279, 130604.

[20] Olasupo, A., and Suah, F.B.M., 2021, Recent advances in the removal of pharmaceuticals and endocrine-disrupting compounds in the aquatic system: A case of polymer inclusion membranes, $J$. Hazard. Mater., 406, 124317.

[21] Kazemi, D., Yaftian, M.R., and Kolev, S.D., 2021, Selective extraction of $\mathrm{Bi}(\mathrm{III})$ from sulfate solutions by a poly(vinyl chloride) based polymer inclusion membrane incorporating bis(2-ethylhexyl) phosphoric acid as the extractant, React. Funct. Polym., 164, 104935.

[22] Abdul Halim, N.S., Whitten, P.G., and Nghiem, L.D., 2016, The effect of aging on thermomechanical and metal extraction properties of poly (vinyl chloride)/Aliquat 336 polymer inclusion membranes, Desalin. Water Treat., 57 (7), 3298-3303. 
[23] Mwakalesi, A.J., and Potter, I.D., 2021, Targeting of cationic organic pesticide residues using polymer inclusion membranes containing anacardic acid from cashew nut shell liquid as a green carrier, $J$. Water Process Eng., 43, 102222.

[24] Chen, L., and Chen, J., 2016, Asymmetric membrane containing ionic liquid [A336][P507] for the preconcentration and separation of heavy rare earth Lutetium, ACS Sustainable Chem. Eng., 4 (5), 26442650.

[25] Carner, C.A., Croft, C.F., Kolev, S.D., and Almeida, M.I.G.S., 2020, Green solvents for the fabrication of polymer inclusion membranes (PIMs), Sep. Purif. Technol., 239, 116486.

[26] Vera, R., Anticó, E., Eguiazábal, J.I., Aranburu, N., and Fontàs, C., 2019, First report on a solvent-free preparation of polymer inclusion membranes with an ionic liquid, Molecules, 24 (10), 1845.

[27] Kaya, A., Onac, C., Alpoğuz, H.K., Agarwal, S., Gupta, V.K., Atar, N., and Yilmaz, A., 2016, Reduced graphene oxide based a novel polymer inclusion membrane: Transport studies of Cr(VI), J. Mol. Liq., $219,1124-1130$.

[28] Matsuoka, H., Aizawa, M., and Suzuki, S., 1980, Uphill transport of uranium across a liquid membrane, J. Membr. Sci., 7 (1), 11-19.

[29] Cho, Y., Xu, C., Cattrall, R.W., and Kolev, S.D., 2011, A polymer inclusion membrane for extracting thiocyanate from weakly alkaline solutions, $J$. Membr. Sci., 367 (1-2), 85-90.

[30] Lee, S.C., Lamb, J.D., Cho, M.H., Rhee, C.H., and Kim, J.S., 2000, A lipophilic acyclic polyether dicarboxylic acid as $\mathrm{Pb}^{2+}$ carrier in polymer inclusion and bulk liquid membranes, Sep. Sci. Technol., 35 (5), 767-778.

[31] Kebiche-Senhadji, O., Mansouri, L., Tingry, S., Seta, P., and Benamor, M., 2008, Facilitated Cd(II) transport across CTA polymer inclusion membrane using anion (Aliquat 336) and cation (D2EHPA) metal carriers, J. Membr. Sci., 310 (1-2), 438-445.

[32] Kaya, A., Onac, C., Alpoguz, H.K., Yilmaz, A., and Atar, N., 2016, Removal of Cr(VI) through calixarene based polymer inclusion membrane from chrome plating bath water, Chem. Eng. J., 283, 141-149.

[33] Kebiche-Senhadji, O., Tingry, S., Seta, P., and Benamor, M., 2010, Selective extraction of $\mathrm{Cr}(\mathrm{VI})$ over metallic species by polymer inclusion membrane (PIM) using anion (Aliquat 336) as carrier, Desalination, 258 (1-3), 59-65.

[34] Ghaderi, N., Dolatyari, L., Kazemi, D., Sharafi, H.R., Shayani-Jam, H., and Yaftian, M.R., 2021, Application of a polymer inclusion membrane made of cellulose triacetate base polymer and trioctylamine for the selective extraction of bismuth(III) from chloride solutions, J. Appl. Polym. Sci., 139 (2), 51480.

[35] Gardner, J.S., Walker, J.O., and Lamb, J.D., 2004, Permeability and durability effects of cellulose polymer variation in polymer inclusion membranes, J. Membr. Sci., 229 (1-2), 87-93.

[36] Kise, H., 1982, Dehydrochlorination of poly(vinyl chloride) by aqueous sodium hydroxide solution under two-phase conditions, J. Polym. Sci., Polym. Chem. Ed., 20 (11), 3189-3197.

[37] Argiropoulos, G., Cattrall, R.W., Hamilton, I.C., Kolev, S.D., and Paimin, R., 1998, The study of a membrane for extracting gold(III) from hydrochloric acid solutions, J. Membr. Sci., 138 (2), 279-285.

[38] Xu, J., Paimin, R., Shen, W., and Wang, X., 2003, An investigation of solubility of Aliquat 336 in different extracted solutions, Fibers Polym., 4 (1), 27-31.

[39] Zhang, C., Mu, Y., Zhao, S., Zhang, W., and Wang, Y., 2020, Lithium extraction from synthetic brine with high $\mathrm{Mg}^{2+} / \mathrm{Li}^{+}$ratio using the polymer inclusion membrane, Desalination, 496, 114710.

[40] Kiswandono, A.A., Siswanta, D., Aprilita, N.H., Santosa, S.J., and Hayashita, T., 2013, Extending the life time of polymer inclusion membrane containing copoly (Eugenol-DVB) as carrier for phenol transport, Indones. J. Chem., 13 (3), 254-261.

[41] Kunene, P., Akinbami, O., Motsoane, N., Tutu, H., Chimuka, L., and Richards, H., 2020, Feasibility of polysulfone as base polymer in a polymer inclusion 
membrane: Synthesis and characterisation, $J$. Membr. Sci. Res., 6 (2), 203-210.

[42] Liu, F., Hashim, N.A., Liu, Y., Abed, M.R.M., and Li, K., 2011, Progress in the production and modification of PVDF membranes, J. Membr. Sci., 375 (1-2), 1-27.

[43] Kozlowski, C., and Walkowiak, W., 2005, Applicability of liquid membranes in chromium(VI) transport with amines as ion carriers, J. Membr. Sci., 266 (1-2), 143-150.

[44] Wang, Z., Sun, Y., Tang, N., Miao, C., Wang, Y., Tang, L., Wang, S., and Yang, X., 2019, Simultaneous extraction and recovery of gold(I) from alkaline solutions using an environmentally benign polymer inclusion membrane with ionic liquid as the carrier, Sep. Purif. Technol., 222, 136-144.

[45] Sun, Y., Wang, Z., Wang, Y., Liu, M., Li, S., Tang, L., Wang, S., Yang, X., and Ji, S., 2020, Improved transport of gold(I) from aurocyanide solution using a green ionic liquid-based polymer inclusion membrane with in-situ electrodeposition, Chem. Eng. Res. Des., 153, 136-145.

[46] Bey, S., Criscuoli, A., Figoli, A., Leopold, A., Simone, S., Benamor, M., and Drioli, E., 2010, Removal of As(V) by PVDF hollow fibers membrane contactors using Aliquat-336 as extractant, Desalination, 264 (3), 193-200.

[47] Sellami, F., Kebiche-Senhadji, O., Marais, S., Colasse, L., and Fatyeyeva, K., 2020, Enhanced removal of $\mathrm{Cr}(\mathrm{VI})$ by polymer inclusion membrane based on poly(vinylidene fluoride) and Aliquat 336, Sep. Purif. Technol., 248, 117038.

[48] Chaouqi, Y., Ouchn, R., Eljaddi, T., Jada, A., El bouchti, M., Cherkaoui, O., and Hlaibi, M., 2019, New polymer inclusion membrane containing NTA as carrier for the recovery of chromium and nickel from textiles wastewater, Mater. Today: Proc., 13, 698-705.

[49] Wang, D., Liu, F., Zhang, X., Wu, M., Wang, F., Liu, J., Wang, J., Liu, Q., and Zeng, H., 2021, A Janus facilitated transport membrane with asymmetric surface wettability and dense/porous structure: Enabling high stability and separation efficiency, $J$. Membr. Sci., 626, 119183.
[50] Huang, S., Chen, J., Chen, L., Zou, D., and Liu, C., 2020, A polymer inclusion membrane functionalized by di(2-ethylhexyl) phosphinic acid with hierarchically ordered porous structure for Lutetium(III) transport, J. Membr. Sci., 593, 117458.

[51] Huang, S., Chen, J., and Zou, D., 2020, A preliminary study of polymer inclusion membrane for lutetium(III) separation and membrane regeneration, J. Rare Earths, 39 (10), 1256-1263.

[52] Guo, L., Liu, Y., Zhang, C., and Chen, J., 2011, Preparation of PVDF-based polymer inclusion membrane using ionic liquid plasticizer and Cyphos IL 104 carrier for $\mathrm{Cr}(\mathrm{VI})$ transport, $J$. Membr. Sci., 372 (1-2), 314-321.

[53] Zioui, D., Arous, O., Mameri, N., Kerdjoudj, H., Sebastian, M.S., Vilas, J.L., Nunes-Pereira, J., and Lanceros-Méndez, S., 2017, Membranes based on polymer miscibility for selective transport and separation of metallic ions, J. Hazard. Mater., 336, 188-194.

[54] Sedkaoui, Y., Abdellaoui, N., Arous, O., Lounici, H., Nasrallah, N., and Szymczyk, A., 2020, Elaboration and characterization of multilayer polymeric membranes: Effect of the chemical nature of polymers, J. Polym. Eng., 41 (2), 127-136.

[55] Wang, Y., Chen, L., Yan, Y., Chen, J., Dai, J., and Dai, X., 2020, Separation of adjacent heavy rare earth Lutetium (III) and Ytterbium (III) by task-specific ionic liquid Cyphos IL 104 embedded polymer inclusion membrane, J. Membr. Sci., 610, 118263.

[56] O'Bryan, Y., Cattrall, R.W., Truong, Y.B., Kyratzis, I.L., and Kolev, S.D., 2016, The use of poly (vinylidenefluoride-co-hexafluoropropylene) for the preparation of polymer inclusion membranes. Application to the extraction of thiocyanate, $J$. Membr. Sci., 510, 481-488.

[57] Bonggotgetsakul, Y.Y.N., Cattrall, R.W., and Kolev, S.D., 2016, Recovery of gold from aqua regia digested electronic scrap using a poly(vinylidene fluoride-co-hexafluoropropene) (PVDF-HFP) based polymer inclusion membrane (PIM) containing Cyphos ${ }^{\circledast}$ IL 104, J. Membr. Sci., 514, 274-281. 
[58] Chae, S.R., Yamamura, H., Ikeda, K., and Watanabe, Y., 2008, Comparison of fouling characteristics of two different poly-vinylidene fluoride microfiltration membranes in a pilot-scale drinking water treatment system using pre-coagulation/sedimentation, sand filtration, and chlorination, Water Res., 42 (8-9), 2029-2042.

[59] Fontàs, C., Anticó, E., Vocanson, F., Lamartine, R., and Seta, P., 2007, Efficient thiacalix[4]arenes for the extraction and separation of $\mathrm{Au}(\mathrm{III}), \mathrm{Pd}(\mathrm{II})$ and $\mathrm{Pt}(\mathrm{IV})$ metal ions from acidic media incorporated in membranes and solid phases, Sep. Purif. Technol., 54 (3), 322-328.

[60] Choe, H.S., Giaccai, J., Alamgir, M., and Abraham, K.M., 1995, Preparation and characterization of poly(vinyl sulfone)- and poly(vinylidene fluoride)based electrolytes, Electrochim. Acta, 40 (13-14), 2289-2293.

[61] Stolarska, M., Niedzicki, L., Borkowska, R., Zalewska, A., and Wieczorek, W., 2007, Structure, transport properties and interfacial stability of $\mathrm{PVdF} / \mathrm{HFP}$ electrolytes containing modified inorganic filler, Electrochim. Acta, 53 (4), 1512-1517.

[62] Guo, L., Zhang, J., Zhang, D., Liu, Y., Deng, Y., and Chen, J., 2012, Preparation of poly(vinylidene fluoride-co-tetrafluoroethylene)-based polymer inclusion membrane using bifunctional ionic liquid extractant for $\mathrm{Cr}(\mathrm{VI})$ transport, Ind. Eng. Chem. Res., 51 (6), 2714-2722.

[63] Bahrami, S., Yaftian, M.R., Najvak, P., Dolatyari, L., Shayani-Jam, H., and Kolev, S.D., 2020, PVDF-HFP based polymer inclusion membranes containing Cyphos $^{\circledast}$ IL 101 and Aliquat 336 for the removal of $\mathrm{Cr}(\mathrm{VI})$ from sulfate solutions, Sep. Purif. Technol., 250, 117251.

[64] Nagul, E.A., Croft, C.F., Cattrall, R.W., and Kolev, S.D., 2019, Nanostructural characterisation of polymer inclusion membranes using X-ray scattering, J. Membr. Sci., 588, 117208.

[65] Wang, D., Liu, J., Chen, J., Liu, Q., and Zeng, H., 2020, New insights into the interfacial behavior and swelling of polymer inclusion membrane (PIM) during Zn(II) extraction process, Chem. Eng. Sci., 220, 115620 .

[66] Wang, D., Cattrall, R.W., Li, J., Almeida, M.I.G.S., Stevens, G.W., and Kolev, S.D., 2017, A poly(vinylidene fluoride-co-hexafluoro propylene) (PVDF-HFP)-based polymer inclusion membrane (PIM) containing LIX84I for the extraction and transport of $\mathrm{Cu}(\mathrm{II})$ from its ammonium sulfate/ ammonia solutions, J. Membr. Sci., 542, 272-279.

[67] Wang, D., Cattrall, R.W., Li, J., Almeida, M.I.G.S., Stevens, G.W., and Kolev, S.D., 2018, A comparison of the use of commercial and diluent free LIX84I in poly(vinylidene fluoride-co-hexafluoro propylene) (PVDF-HFP)-based polymer inclusion membranes for the extraction and transport of $\mathrm{Cu}(\mathrm{II})$, Sep. Purif. Technol., 202, 59-66.

[68] Fajar, A.T.N., Kubota, F., Firmansyah, M.L., and Goto, M., 2019, Separation of palladium(II) and rhodium(III) using a polymer inclusion membrane containing a phosphonium-based ionic liquid carrier, Ind. Eng. Chem. Res., 58 (49), 22334-22342.

[69] Fajar, A.T.N., Hanada, T., Firmansyah, M.L., Kubota, F., and Goto, M., 2020, Selective separation of platinum group metals via sequential transport through polymer inclusion membranes containing an ionic liquid carrier, ACS Sustainable Chem. Eng., 8 (30), 11283-11291.

[70] Fajar, A.T.N., Hanada, T., and Goto, M., 2021, Recovery of platinum group metals from a spent automotive catalyst using polymer inclusion membranes containing an ionic liquid carrier, $J$. Membr. Sci., 629, 119296.

[71] Xiong, X., Almeida, M.I.G.S., Simeonova, S., Spassov, T.G., Cattrall, R.W., and Kolev, S.D., 2019, The potential of polystyrene-block-polybutadieneblock-polystyrene triblock copolymer as a basepolymer of polymer inclusion membranes (PIMs), Sep. Purif. Technol., 229, 115800.

[72] Xiong, X., Zhang, L., Ma, Z., and Li, Y., 2005, Effects of molecular weight and arm number on properties of star-shape styrene-butadiene-styrene triblock copolymer, J. Appl. Polym. Sci., 95 (4), 832-840. 
[73] Turgut, H.I., Eyupoglu, V., Kumbasar, R.A., and Sisman, I., 2017, Alkyl chain length dependent $\mathrm{Cr}(\mathrm{VI})$ transport by polymer inclusion membrane using room temperature ionic liquids as carrier and PVDF-co-HFP as polymer matrix, Sep. Purif. Technol., 175, 406-417.

[74] Yaftian, M.R., Almeida, M.I.G.S., Cattrall, R.W., and Kolev, S.D., 2018, Selective extraction of vanadium(V) from sulfate solutions into a polymer inclusion membrane composed of poly(vinylidenefluoride-cohexafluoropropylene) and Cyphos ${ }^{\otimes}$ IL 101, J. Membr. Sci., 545, 57-65.

[75] Hanada, T., Firmansyah, M.L., Yoshida, W., Kubota, F., Kolev, S.D., and Goto, M., 2020, Transport of rhodium(III) from chloride media across a polymer inclusion membrane containing an ionic liquid metal ion carrier, ACS Omega, 5 (22), 12989-12995.

[76] Wang, B., Li, Z., Lang, Q., Tan, M., Ratanatamskul, C., Lee, M., Liu, Y., and Zhang, Y., 2020, A comprehensive investigation on the components in ionic liquid-based polymer inclusion membrane for $\mathrm{Cr}(\mathrm{VI})$ transport during electrodialysis, J. Membr. Sci., 604, 118016.

[77] Scindia, Y.M., Pandey, A.K., Reddy, A.V.R., and Manohar, S.B., 2002, Selective pre-concentration and determination of chromium(VI) using a flat sheet polymer inclusion sorbent: Potential application for $\mathrm{Cr}(\mathrm{VI})$ determination in real samples, Anal. Chem., 74 (16), 4204-4212.

[78] Kozlowski, C.A., and Walkowiak, W., 2004, Transport of $\mathrm{Cr}(\mathrm{VI}), \mathrm{Zn}(\mathrm{II})$, and $\mathrm{Cd}(\mathrm{II})$ ions across polymer inclusion membranes with tridecyl(pyridine) oxide and tri-n-Octylamine, Sep. Sci. Technol., 39 (13), 3127-3141.

[79] Nielsen, L.E., 1969, Cross-linking-effect on physical properties of polymers, J. Macromol. Sci., Polym.
Rev., 3 (1), 69-103.

[80] Decker, C., 1999, Recent developments in photoinitiated radical polymerization, Macromol. Symp., 143 (1), 45-63.

[81] O'Bryan, Y., Truong, Y.B., Cattrall, R.W., Kyratzis, I.L., and Kolev, S.D., 2017, A new generation of highly stable and permeable polymer inclusion membranes (PIMs) with their carrier immobilized in a cross-linked semi-interpenetrating polymer network. Application to the transport of thiocyanate, J. Membr. Sci., 529, 55-62.

[82] Hoque, B., Almeida, M.I.G.S., Cattrall, R.W., Gopakumar, T.G., and Kolev, S.D., 2019, Effect of cross-linking on the performance of polymer inclusion membranes (PIMs) for the extraction, transport and separation of $\mathrm{Zn}(\mathrm{II})$, J. Membr. Sci., $589,117256$.

[83] Hoque, B., Almeida, M.I.G.S., Cattrall, R.W., Gopakumar, T.G., and Kolev, S.D., 2021, Improving the extraction performance of polymer inclusion membranes by cross-linking their polymeric backbone, React. Funct. Polym., 160, 104813.

[84] Hoque, B., Kolev, S.D., Cattrall, R.W., Gopakumar, T.G., and Almeida, M.I.G.S., 2021, A cross-linked polymer inclusion membrane for enhanced gold recovery from electronic waste, Waste Manage., 124, 54-62.

[85] Darvishi, R., Karimi-Sabet, J., and Esfahany, M.N., 2018, Preparation and characterization of a novel calcium-conducting polymer inclusion membrane: Part I, Korean J. Chem. Eng., 35 (10), 2052-2064.

[86] Kazemzadeh, H., Karimi-Sabet, J., Towfighi Darian, J., and Adhami, A., 2020, Evaluation of polymer inclusion membrane efficiency in selective separation of lithium ion from aqueous solution, Sep. Purif. Technol., 251, 117298. 